\title{
REFLEXIONS SUR LES CONCEPTS EN DROIT DE L'ENVIRONNEMENT
}

\author{
Adeline Meynier \\ Editorial LGFJ \\ París. 2020. \\ $599 \mathrm{pp}$
}

ISBN 978-2-275-06453-6

La presente monografía de Adeline MEYNIER tiene origen en su tesis doctoral elaborada en el seno del prestigioso Instituto de Derecho ambiental de la Universidad «Jean Moulin» (Lyon III) que, con tanto acierto, dirige el profesor Philippe BILLET. El completo y detallado análisis realizado demuestra toda la complejidad y dificultad de la tarea de construir el derecho ambiental como una rama jurídica coherente y dotada, cada vez más, de sus propios conceptos. La necesidad de establecer un difícil orden en este mundo conceptual de la disciplina jurídica ambiental exige analizar, mediante aproximaciones sucesivas, los diversos conceptos unificadores, próximos a los valores, y los conceptos organizadores, surgidos de la ecología, o de otras disciplinas. En concreto, la autora ha seguido en su ordenación de los conceptos la distinción entre aquellos "descriptivos», que se caracterizan por su poder de nombrar, es decir, de hacer que adquieran existencia jurídica realidades tan complejas como puede ser la del mismo medio ambiente (I cuya función consiste en intervenir sobre la realidad ecológica, fijando objetivos y definiendo derechos y obligaciones (III parte, pp. 295-526).

Estas dos partes que estructuran la obra van divididas a su vez en títulos, capítulos y secciones, lo que pone de manifiesto una encomiable voluntad de claridad y de coherencia expositiva, que se refuerza por las conclusiones que condensan los resultados más destacados de la investigación realizada y que se insertan al final de cada uno de los capítulos y de las partes. La estructura de la monografía se completa con un prólogo a cargo del profesor Jean UNTERMAIER (pp. IX-XI), las reflexiones introductorias a cargo de la autora (pp. 1-28), un epílogo del profesor Philippe BILlet (pp. 577-578), así como una completa 
recopilación bibliográfica (pp. 531-563), un índice de jurisprudencia (pp. 565575), y un índice analítico (pp. 579-580) y otro por materias (pp. 583-599).

La meticulosa y exhaustiva investigación realizada pone de manifiesto, en un primer momento, que las preocupaciones ambientales llevaron a la doctrina a detectar los límites de las reglas jurídicas tradicionales que se muestran inadecuadas para enfrentar la crisis ecológica; en particular, no permiten integrar de manera coherente los elementos que forman el medio ambiente. Este conjunto de reflexiones, que integran el primer capítulo («Los conceptos generales, objetos del derecho ambiental», pp. 35- 87) del Tít. I («La descripción del medio ambiente y de sus elementos», pp. 33-183) de la la parte de la monografía, subrayan cómo, en sus orígenes, el derecho toma en consideración ciertos elementos de la naturaleza considerados como recursos naturales a fin de regular su explotación (p. 37). De este modo, el propio concepto de «naturaleza» nos aparece como una construcción social evolutiva de acuerdo con las diferentes políticas públicas, las necesidades y las aspiraciones de la sociedad que van permeando en diferentes épocas el derecho. La volatilidad del concepto se ve reforzada por una definición jurídica a priori incierta (p. 39) lo que determina su progresiva sustitución por el concepto de «medio ambiente» (pp. 43-55).

En el capítulo segundo («Los conceptos especiales, objetos de derecho», pp. 89-177) se evidencia que el ordenamiento jurídico se enfrenta al obstáculo de la complejidad de la naturaleza, de las cambiantes interacciones entre los diversos componentes del medio ambiente y sus evolutivos procesos ecológicos, a los que, de acuerdo a su modus operandi metodológico tradicional —la fragmentación de la realidad en objetos tratados de manera separada- no puede atender de manera adecuada. El derecho ha debido pues incorporar conceptos como los de «especie» (p. 94) y «población» (p. 99), a partir de los cuales se construyen categorías jurídicas con perfiles específicos, en una dialéctica construida a partir de los conocimientos científicos pero que incorpora objetivos específicamente jurídicos. Esta progresiva juridificación de una realidad definida desde la ecología queda patente en relación a los conceptos de «ecosistema» y de «hábitat» (pp. 132-136). En la actualidad, el concepto de «biodiversidad» se impone para describir y aprehender jurídicamente lo vivo en toda su globalidad y complejidad. En este sentido, constituye un metaconcepto 
que tiende a reemplazar al de «naturaleza» y al de «medio ambiente» para estructurar los contenidos y objetivos de todo el derecho ambiental (p. 166 y ss.). El concepto de «contaminación» abre las reflexiones del Título II de esta primera parte de la monografía (p. 188). Además de destacar el tratamiento jurídico sectorial, la autora subraya que en relación al grado de contaminación persisten dos enfoques diferentes. Para unos, la diferencia entre la emisión de una sustancia y la contaminación está ligado a la superación de un límite establecido para evitar la aparición del daño ecológico (p. 196). Según la segunda concepción, la contaminación existe por la sola presencia de un daño, independientemente de todo límite o exigencia suplementaria requerida por la norma. Se trata por tanto, en este caso, de una definición amplia de la noción de contaminación que tiene sobre todo en cuenta la degradación de la calidad del medio más que la cantidad de sustancia o de energía emitida. De manera acertada apunta que debe primar el criterio finalista en la noción de contaminación, si se tiene además en cuenta que el interés protegido por el derecho no consiste sólo en la defensa del medio natural sino que también están en juego otros derechos como la salud y la propia supervivencia de actividades económicas ligadas al mantenimiento de la calidad ambiental, como las actividades recreativas y el turismo (p. 198). Especial atención reciben también conceptos como el de «residuo», piedra angular de todo un sector de regulación ambiental (pp. 207-231) y, sobre todo, el de riesgo, categoría jurídica a la que atribuye el papel de nuevo paradigma desde el que enfocar los estudios jurídicoambientales (pp. 231-244).

El capítulo segundo, que cierra esta primera parte del libro, estudia "Los conceptos generales relativos a todas las afecciones al medio" (pp. 247-287). Se analiza de este modo la consagración específica en el derecho ambiental de los conceptos de daño (dommage) y lesión ecológica (préjudice) (pp. 248-269). Por otra parte, el «valor de referencia» o umbral (seuil) constituye un concepto central del derecho ambiental que refleja una lógica de adaptación del derecho a las diferentes realidades ambientales y las variadas clases de afecciones al medio (p. 270).

La II므 parte se inicia con unas afinadas reflexiones sobre el «interés general» de la protección del medio como piedra angular del derecho ambiental (pp. 313-323) que conducen, de manera necesaria, a atisbar sus propios límites económicos y 
científicos (pp. 323-355). Así, señala MEYNIER que "los estándares del «coste económico aceptable», de los «conocimientos científicos y técnicos del momento» y de las «mejores técnicas disponibles», condicionan la aplicabilidad del derecho ambiental e iluminan una cierta conceptualización de los límites económicos y de los derivados de la evolución de los conocimientos científicos y del progreso técnico de la protección ambiental" (p. 337). El segundo acápite examina "los objetivos de una buena calidad ambiental" (pp. 359-414) donde se aborda la exigencia de un "nivel de protección elevado y de mejora de la calidad del medio ambiente" en el Derecho de la UE que presupone la necesaria toma en consideración de la evolución científica (p. 370). Estas consideraciones se aplican de modo sectorial al buen estado de las masas de agua (pp. 382-395), a la buena calidad del aire ambiente (pp. 395-405) y, en fin, al estado de conservación favorable de las especies o de los hábitats (pp. 405-414).

A los conceptos que renuevan la protección ambiental se dedica el Título II de la segunda parte (pp. 419-523) y, entre ellos, ocupa un lugar destacado el concepto de «desarrollo sostenible» (Cap. 1, pp. 421-474). Sobre las controversias derivadas de la ambigüedad de este concepto basilar y las sugerencias para su sustitución afirma la autora que "las propuestas en este sentido no han sido por el momento acogidas. En un contexto fuertemente marcado por el triunfo de la ideología liberal, el realismo jurídico determina la conservación del término desarrollo" (p. 443). La obra dedica su último capítulo a la "democracia ambiental», concepto emergente que tiende a vertebrar el derecho ambiental asignándole un objetivo cada vez más preciso (pp. 506-520).

En conclusión, la obra trata de responder al interrogante fundamental acerca de si el derecho está suficientemente dotado de conceptos propios para enfrentar los urgentes y esenciales retos que nos plantean las cuestiones ambientales en esta época en la que ha irrumpido con toda su fuerza la crisis climática. La Dra. MEYNIER consigue demostrar cómo, de manera efectiva, la emergente dimensión conceptual se corresponde con la madurez alcanzada por el derecho ambiental. Sirvan estas sintéticas referencias - pálido reflejo de la enorme riqueza de sus contenidos y de la profundidad de la investigación realizada - como viva recomendación para su lectura que nos abre nuevas y fructíferas perspectivas. 
RCDA Vol. XI Núm. 2 (2020)

Profesor Titular de Derecho Administrativo

Universidad de Murcia (España) 